\title{
Vitamin and essential trace element recommendations during intravenous nutrition: theory and practice
}

\author{
By A. Shenkin, Department of Biochemistry, Royal Infirmary Glasgow $G_{4} \circ S F$
}

The main objectives in provision of essential micronutrients, whether organic (vitamins) or inorganic (trace elements) are to ensure optimal utilization of the major dietary constituents and hence obtain optimal tissue function. This view is idealistic and, though admirable in theory, is far from attainable in practice, mainly due to the lack of suitable methods of assessing tissue function. Difficult though this may be in patients receiving a normal oral diet, there are special problems in the patient fed intravenously which further complicate the situation.

\section{Vitamin and trace element provision during intravenous nutrition (IVN): theory}

One method of meeting the requirements for micronutrients during IVN would, in theory, be to provide the individual micronutrients intravenously, in the same amount and chemical form as would be absorbed into the portal vein from the intestinal tract, from an adequate oral diet. There are obvious difficulties with this.

Which micronutrients to provide? The first problem is which of the micronutrients present in an adequate oral diet should be provided intravenously. Such an oral diet will contain not only those nutrients definitely known to be essential in man (all the vitamins plus the trace elements zinc, iron, copper, iodine, manganese, molybdenum, cobalt, selenium, chromium), but also those which are essential in animals but not yet proven to be essential in man (tin, arsenic, nickel, silicon, vanadium). Moreover, fluoride occupies a rather special situation, in that it may not be essential in 'classical' terms, but is nonetheless beneficial for long-term health. Because of the complexities of provision of IVN, as well as the lack of guidelines, only those essential inorganic and organic micronutrients definitely known to be essential need be considered at present, when planning IVN. If any of the other inorganic micronutrients are indeed essential in man, it is generally assumed that they will be provided in adequate amounts as contaminants of the intravenous preparations, and that specific provision need not be made. By definition, there is no evidence for this at present.

How much of any nutrient is absorbed from the gastrointestinal tract? Balance studies have been used for most inorganic nutrients and to a lesser extent for vitamins, to determine the proportion of individual nutrients absorbed. However, this is by no means constant. The overall composition of the diet markedly alters the availability of the nutrients. The amount of dietary fibre affects the proportion of $\mathrm{Cu}, \mathrm{Zn}$ and $\mathrm{Mg}$ absorbed (Drews \& Kies, 1979), and $\mathrm{Zn}$ absorption from soya-bean products is reduced by phytate (Lonnerdal et al. 1984). Similarly, it has 
been known for more than 30 years that B-vitamin absorption from certain vegetables is poor in comparison with their absorption from milk products (Everson et al. 1948). On the other hand, enhanced absorption of certain forms of micronutrients can occur, for example, the organic complex of $\mathrm{Cr}$ (Anderson et al. I 980) and haem-Fe are better absorbed than their respective inorganic salts. Even the valency state may be important, since ferrous-Fe is better absorbed than ferric-Fe.

These variations are further confounded by the interactions which may occur between nutrients. Certain elements compete for similar absorption pathways, so that $\mathrm{Zn}$ absorption may be inhibited by inorganic $\mathrm{Fe}$ (Valberg et al. 1984 ), whereas a high $\mathrm{Zn}$ intake may reduce $\mathrm{Cu}$ absorption (Fischer et al. 1984). Ascorbic acid improves $\mathrm{Fe}$ absorption, possibly by increasing the amount of $\mathrm{Fe}^{2+}$, but at the same time it reduces absorption of $\mathrm{Cu}$ (Solomons \& Viteri, I982).

Apart from the composition of the diet, the amount absorbed may be controlled by the physiological state of the individual. In Fe deficiency, mucosal transport of $\mathrm{Fe}$ increases so that a higher proportion is absorbed, and greater quantities of transferrin are synthesized and are present in blood to increase transport of $\mathrm{Fe}$ to the bone marrow. This physiological control mechanism is by-passed during intravenous nutrition, and this may be significant both from the point of view of increasing intake when necessary, as well as by protecting the body from excess provision. Recommendations for intravenous use therefore are required to be more accurate than those for enteral use.

All these factors lead to variation in the amount of nutrient absorbed from a particular diet. It is therefore not surprising that for many of the micronutrients, especially trace elements, recommended dietary intakes have not been established. Ranges of amounts considered to be safe and adequate in an oral diet (but not necessarily optimal) have been indicated by the Food and Nutrition Board (1980) of the United States. However, these levels of intake are not particularly helpful in establishing requirements during IVN because of the variability in the proportion absorbed.

Does intravenous infusion of nutrients alter micronutrient requirements? Even if clear recommendations could be made for the amount and chemical form of each nutrient absorbed from the gastrointestinal tract, the technology of IVN introduces further variables which alter the amounts of the micronutrients which should be provided. Fat-soluble vitamins may be absorbed onto PVC bags, and a case of vitamin $A$ deficiency has been recorded as a result of this (Howard et al. 1980). Because the solutions are usually infused at room temperature for $24 \mathrm{~h}$, u.v. light may lead to significant degradation of retinol (Allwood, I982) and riboflavin (Chen et al. 1983). Measures should be taken to minimize such absorption and degradation, possibly by using ethylvinyl acetate (EVA) bags, by covering the bags with u.v. light-impermeable material, or by infusing the vitamins in the fat emulsion.

The current trend is towards infusion of a complete mixture of all nutrients in one single bag. Although technically more simple, this is likely to encourage 


\section{Vol. 45 Nutrient recommendations for man-theory and practice 385}

chemical interactions between nutrients. For example, trace elements may complex with amino acids or other components, leading to an increased excretion of $\mathrm{Zn}$ in the urine (Shenkin et al. 1985). Where the trace elements can interact with vitamins within the one bag, $\mathrm{Cu}$ may oxidize ascorbic acid, resulting in rapid loss of vitamin $\mathrm{C}$ from the nutritive mixture (Allwood, 1984). This may be of limited practical importance, at least in the short term, since we have found that provision of IVN from such a mixture leads to similar blood concentrations of vitamins and essential elements to those found when interactions are prevented by use of separate infusions of vitamins and trace elements.

A further question, relevant to all the nutrients, is whether continuous $24 \mathrm{~h}$ infusion alters metabolic requirements and handling. Intravenous nutrient intake is obviously quite different from oral intake in this respect. There is no information which compares different rates of infusion of micronutrients.

Do patients receiving IVN have different nutritional requirements from normal individuals? Patients who require IVN have a disease process which renders impossible an adequate oral or enteral intake. Some of these patients may have chronic intestinal failure and are sufficiently stable for long-term maintenance IVN to be provided. In such patients, requirements for all nutrients fit the previously described definition regarding absorption from an adequate oral diet.

However, most patients fed intravenously are acutely ill, and many have a catabolic, tissue-wasting disease process, with increased requirements for protein and energy (Kinney et al. 1970). Alternatively, they may have been ill for several days, or weeks, and already be severely depleted. It can be reasoned that such patients should therefore have a higher requirement for micronutrients, both as metabolic cofactors to improve utilization of protein and energy substrates, as well as being chemical components themselves necessary for synthesis and incorporation into new tissues. Various workers have speculated that this increase may range from two times to ten times the basal requirement, especially for vitamins. Some attempts have been made to study trace element requirements in patients with increased losses. Wolman et al. (r 979) have measured the greater requirement for $\mathbf{Z n}$ in patients with substantial gastrointestinal losses, whereas Shike et al. (198r) found that Cu losses from the gut are usually not large. Studies during correction of depletion or tissue regeneration have not been made and, therefore, accurate recommendations in such situations are not available.

How can optimal requirements be defined? The overriding difficulty in all studies of micronutrient requirements is the lack of suitable markers of tissue status or function. There are many biochemical tests of vitamin and trace element status, but interpretation is often limited. Blood or urine samples usually do not reflect tissue status, although in the stable patient, trends in blood values may offer an indication of the adequacy or otherwise of the level of intake. Balance studies, although helpful, do not indicate whether individual tissues have been maintained or have been adequately repleted with the nutrient under study. Tissue analysis is rarely practicable in man. Enzyme activities, such as erythrocyte or platelet glutathione peroxidase ( $E C$ I.II.I.9; as an index of Se status), or erythrocyte 
transketolase ( $E C$ 2.2.1.1) activation (for thiamin status) are currently the best type of markers of tissue function but even these do not necessarily reflect differences in body pools or between tissues. Thus virtually all recommendations for intravenous use are based on inadequate experimental information, and for none can it be concluded that provision is 'optimal' in terms of achieving 'optimal tissue function'. New markers of tissue function suitable for use in the ill patient are required.

\section{Vitamin and essential trace element provision in practice}

Despite this lack of adequate information for determining the amounts of individual nutrients, the practising clinician requires recommendations for levels of supply to enable him to provide IVN as safely and effectively as possible. Many sets of guidelines have appeared in the literature (Shils, 1972; Wretlind, 1972; Jacobson \& Wester, 1977; Shenkin \& Wretlind, 1978; American Medical Association, 1979a,b; Jeejeebhoy, 1983 ). These are usually based on the theoretical estimates from knowledge of oral intake, together with the clinical and biochemical response to intravenous provision at different levels.

\section{Essential trace element provision}

There are two main approaches to essential trace element provision, either to use infusions of individual elements, or to use a mixture of trace elements. The American Medical Association (1979a) Expert Panel recommended that preparations of individual trace elements should be available; specifically recommended were individual preparations of $\mathrm{Zn}, \mathrm{Cu}, \mathrm{Cr}$ and $\mathrm{Mn}$. They pointed out that this allows maximum flexibility so that greater amounts of one element can be provided when necessary, without causing overprovision of the other elements. Although this has theoretical advantages, it is clearly more labour intensive for the pharmacist to make four (or more) separate additions, than to make one addition of a suitable mixture. The question arises as to how often it is necessary to take advantage of the flexibility of the separate infusion system; in other words, to what extent is it possible to standardize infusions with a single mixture?

We have studied the use of a mixture of nine trace elements which provides $\mathrm{Zn}$, $\mathrm{Cu}, \mathrm{Fe}, \mathrm{Mn}, \mathrm{Cr}, \mathrm{Se}, \mathrm{Mo}, \mathrm{F}$ and I (Shenkin et al. 1985) (Table I). The levels of different elements were chosen in an attempt to meet the basal or moderately increased requirements of patients who may be stable, have somewhat increased losses, or have a depletion state requiring correction. Postoperative surgical patients comprise the majority of patients requiring IVN, and this mixture has been found to maintain or correct serum and urine concentrations of most of these elements for such patients. The level of Se provision $(30 \mu \mathrm{g}(400 \mathrm{nmol}) / \mathrm{d})$ is adequate to maintain Se status, but not correct a depletion state. Mn requirements in IVN were previously considered to be about $40 \mu \mathrm{mol} / \mathrm{d}$ (Wretlind, 1972) but even $15 \mu \mathrm{mol} / \mathrm{d}$ has been found by us to lead to high serum Mn concentrations. A dose of $5 \mu \mathrm{mol} \mathrm{Mn} / \mathrm{d}$ appears adequate to maintain serum $\mathrm{Mn}$ in the normal range. 


\section{Vol. 45 Nutrient recommendations for man - theory and practice 387}

Serum and urine $\mathrm{Cr}$ is usually increased in patients receiving IVN. This is probably in part due to the requirement for $\mathrm{Cr}$ in the metabolism of glucose, and $\mathrm{Cr}$ is therefore mobilized from tissue stores in response to the glucose load during IVN. However, we have also found that serum $\mathrm{Cr}$ level relates to the amount of $\mathrm{Cr}$ present in the food, often as an accidental contaminant, especially from intravenous amino acid preparations which have $\mathrm{Cr}$ levels ranging from $50 \mathrm{nmol} / 1$ to more than $1000 \mathrm{nmol} / \mathrm{l}$. The adult requirement for intravenous $\mathrm{Cr}$ is probably about $200-400 \mathrm{nmol} / \mathrm{d}$ (American Medical Association, 1979a). We have found that serum and urine $\mathrm{Cr}$ is higher in patients receiving total parenteral nutrition infusions which are rich in $\mathrm{Cr}$. The essentiality of $\mathrm{Cr}$ provision during IVN should therefore be questioned. Our present evidence suggests that it is not essential in short-term IVN, but in patients receiving home IVN with preparations low in $\mathrm{Cr}$, supplements may be necessary. In practical terms, a slight excess provision of $\mathrm{Cr}$ is probably not harmful, since it is readily excreted in the urine.

A mixture of elements can therefore be used in the majority of patients. Some patients may have a particular requirement for an individual element, e.g. if there is clinical evidence of $\mathrm{Zn}$ or $\mathrm{Cu}$ deficiency, or if there is biochemical evidence of Se depletion, and in these cases individual element supplements should be given, in addition to the multi-element mixture.

A further area of current interest in which there is relatively little information is the optimal chemical form of the individual elements to be used in intravenous supplements. Sodium selenite has been widely used as a source of Se and it is known to be incorporated into selenoenzymes, and to correct Se deficiency states. However, it is highly reactive chemically, and is liable to reduction by ascorbic acid to elemental Se. The significance of this observation in practice is not known. Selenomethionine is an alternative chemical source of Se which is more effectively retained by the body when given intravenously (Van Rij et al. 1981). However, this may be due to its incorporation into proteins and the Se may not be fully available for use elsewhere. Sodium selenate has recently been suggested as a more suitable form of Se supplement (Levander, 1984). Further study on the chemical form of elements for intravenous use is clearly necessary.

\section{Vitamin provision}

Vitamin deficiency syndromes during IVN have been reported for virtually all the vitamins. These have always occurred in patients where provision was known to be inadequate. However, with the availability of multi-vitamin mixtures suitable for intravenous use, vitamin status has been improved. The amounts of vitamins present in older versions of such preparations were usually chosen to conform to the recommended daily allowances for oral intake, and although in many cases these were adequate, biochemical correction of vitamin status was not always achieved (Stromberg et al. 1981). More recent recommendations have made an allowance for the special requirement of the ill patient requiring IVN (American Medical Association, 1979b). We have found that the use of the mixture shown in Table 1, which was based on the American Medical Association (1979b) 


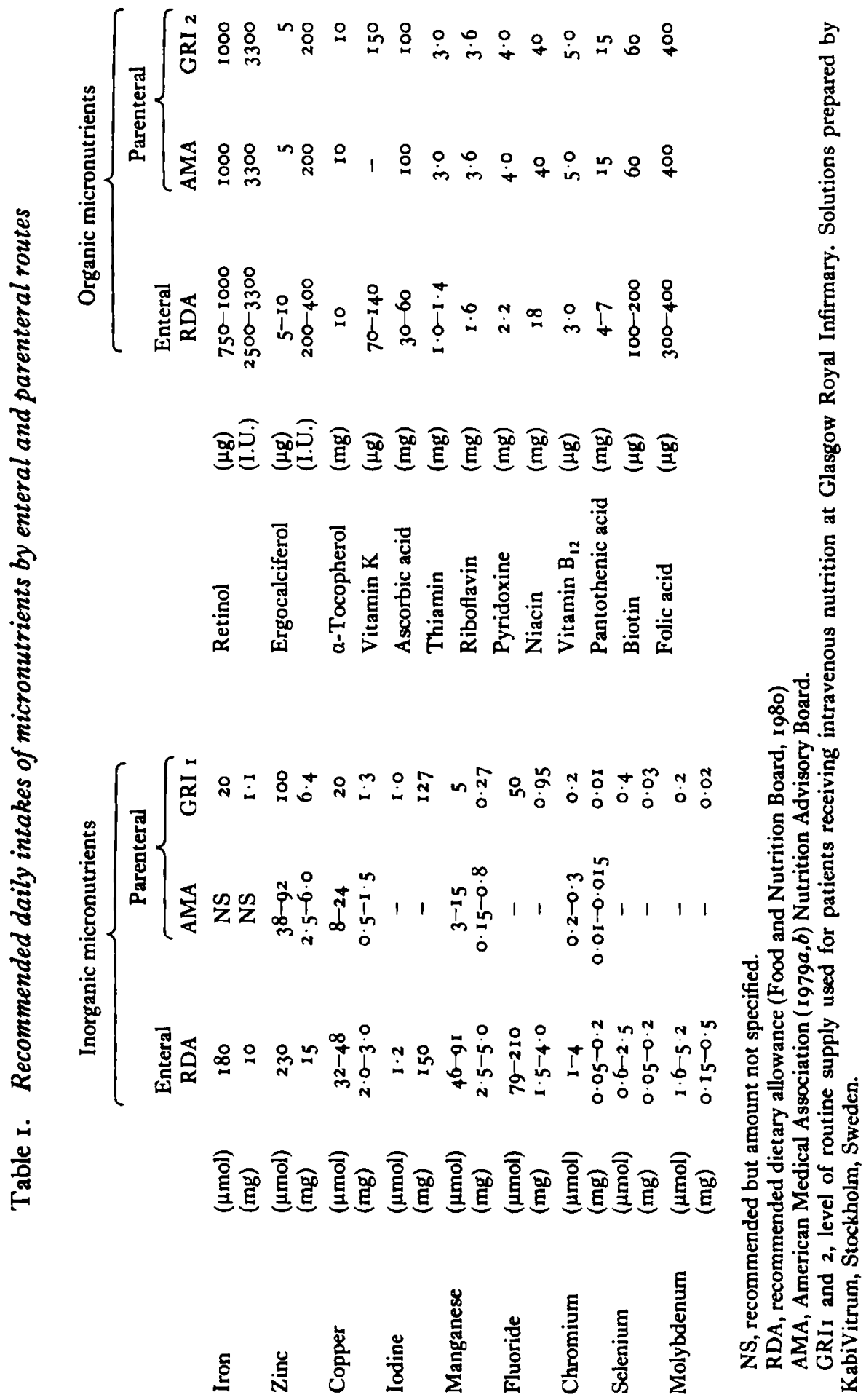




\section{Vol. 45 Nutrient recommendations for man - theory and practice}

recommendations, leads to normal blood biochemistry in short-term studies (2-4 weeks) of postoperative surgical patients and Shils et al. (1985) have shown that it is also adequate for stable patients receiving long-term IVN. From a practical point of view, these supplements should be given in a fat emulsion, preferably on a daily basis, in order to protect them from u.v. light. It has been recommended that vitamins should not be infused in the same bag as trace elements (Allwood, 1984) although our short-term evidence does not support this conclusion. Longer-term studies of the effects of complete nutritive mixtures on micronutrient status are necessary.

\section{Conclusions}

Recommendations for essential trace element and vitamin provision during IVN are now available (Table $\mathrm{r}$ ). Clinical experience of the use of multi-element and multi-vitamin mixtures has demonstrated that correction or maintenance of normal blood levels can be achieved in most patients requiring IVN. Moreover, clinical deficiency states have not been observed in patients receiving such mixtures even over prolonged periods. Levels of provision for patients with abnormal requirements, for example severe hypercatabolism or renal failure, have not been considered in this review. Future work will require study of the requirements of such special groups of patients. Better markers of micronutrient status, especially of tissue function are necessary to permit more accurate definition of requirements in disease states and the most appropriate method of infusion of the micronutrients.

\section{REFERENCES}

Allwood, M. C. (1982). Clinical Nutrition 1, 63-70.

Allwood, M. C. (1984). Foumal of Clinical Hospital Pharmacy 9, $18 \mathrm{I}-198$.

American Medical Association (1979a). Fournal of Parenteral and Enteral Nutrition 3, 263-267.

American Medical Association (1979b). Foumal of Parenteral and Enteral Nutrition 3, 258-262.

Anderson, M., Riley, D. \& Rotrick, J. (1980). Federation Proceedings 39, 787.

Chen, M. F., Boyce, H. W. \& Triplett, C. (1983). Fournal of Parenteral and Enteral Nutrition 7, $462-464$.

Drews, L. M. \& Kies, H. M. (1979). American Fournal of Clinical Nutrition 32, 1893-1897.

Everson, G., Wheeler, E., Walker, H. \& Caulfield, W. J. (1948). Fournal of Nutrition 35, 209-223.

Fischer, P. W. F., Giroux, A. \& Abbe, M. R. L. (1984). American fournal of Clinical Nutrition $40,743-746$.

Food and Nutrition Board (1980). Recommended Dietary Allowances, gth ed. Washington DC: National Academy of Sciences.

Howard, L., Chu, R., Feman, S., Mintz, H., Ovesen, L. \& Wolf, B. (1980). Annals of Internal Medicine 93, 576-577.

Jacobson, S. \& Wester, P. O. (1977). British Fournal of Nutrition 37, 107-1 26.

Jeejeebhoy, K. N. (1983). In New Aspects of Clinical Nutrition, pp. I-24 [G. Kleinberger and E. Deutsch, editor]. Basel: Karger.

Kinney, J. M., Long, C. L. \& Duke, J. H. (1970). In Energy Metabolism and Trauma, pp. 103-126 [R. Porter and J. Knight, editors]. London: Churchill.

Levander, O. A. (1984). Bulletin of New York Academy of Medicine 60, 144-155.

Lonnerdal, B., Cederblad, A., Davidson, L. \& Sandstrom, B. (1984). American Fournal of Clinical Nutrition 40, 1064-1070. 
Shenkin, A., Smith, A. D. S., Fell, G. S., Halls, D. J., Nigdikar, S., Dunbar, P. M., Harris, N. W. S. \& Sim, A. J. W. (1985). Nutrition Research Suppl. I, 209-2 2.

Shenkin, A. \& Wretlind, A. (1978). World Review of Nutrition and Dietetics 28, I-1 11 .

Shike, M., Roulet, M., Kurian, R., Whitwell, J., Stewart, S. \& Jeejeebhoy, K. N. (1981). Gastroenterology 8x, 290-297.

Shils, M. E. (1972). Drug Intelligence and Clinical Pharmacy 6, 386-393.

Shils, M. E., Baker, H. \& Frank D. (1985). Foumal of Parenteral and Enteral Nutrition 9, 179-188.

Solomons, N. W. \& Viteri, F. E. (1982). In Ascorbic Acid Chemistry, Mechanism and Uses, pp. 557-569 [P. Seib and B. Tolbert, editors]. Washington DC: American Chemical Society.

Stromberg, P., Shenkin, A., Campbell, R. A., Spooner, R. J., Davidson, J. F. \& Sim, A. J. W. (1981). Fournal of Parenteral and Enteral Nutrition 5, 295-299.

Valberg, L. S., Flanagan, P. R. \& Chamberlain, M. J. (1984). American fournal of Clinical Nutrition 40, 536-541.

Van Rij, A. M., McKenzie, J. M., Thomson, C. D. \& Robinson, M. F. (1981). Fournal of Parenteral and Enteral Nutrition 5, 120-124.

Wolman, S. L., Anderson, G. H., Marliss, E. B. \& Jeejeebhoy, K. N. (1979). Gastroenterology 76, $45^{8-467 .}$

Wretlind, A. (1972). Nutrition and Metabolism Suppl. 14, 1-57. 